\title{
A Review of MR Spectroscopy Studies of Pediatric Bipolar Disorder
}

\author{
D.G. Kondo, T.L. Hellem, X.-F. Shi, Y.H. Sung, A.P. Prescot, T.S. Kim, R.S. Huber, L.N. Forrest, and P.F. Renshaw
}

\begin{abstract}
Pediatric bipolar disorder is a severe mental illness whose pathophysiology is poorly understood and for which there is an urgent need for improved diagnosis and treatment. MR spectroscopy is a neuroimaging method capable of in vivo measurement of neurochemicals relevant to bipolar disorder neurobiology. MR spectroscopy studies of adult bipolar disorder provide consistent evidence for alterations in the glutamate system and mitochondrial function. In bipolar disorder, these 2 phenomena may be linked because $85 \%$ of glucose in the brain is consumed by glutamatergic neurotransmission and the conversion of glutamate to glutamine. The purpose of this article is to review the MR spectroscopic imaging literature in pediatric bipolar disorder, at-risk samples, and severe mood dysregulation, with a focus on the published findings that are relevant to glutamatergic and mitochondrial functioning. Potential directions for future MR spectroscopy studies of the glutamate system and mitochondrial dysfunction in pediatric bipolar disorder are discussed.
\end{abstract}

ABBREVIATIONS: $\mathrm{ACC}=$ anterior cingulate cortex; $\mathrm{ATP}=$ adenosine triphosphate; $\mathrm{BD}=$ bipolar disorder; $\mathrm{GABA}=\gamma$-aminobutyric acid; $\mathrm{Gln}=$ glutamine; $\mathrm{Glu}=$ glutamate; $\mathrm{HC}=$ healthy controls; $\mathrm{PCr}=$ phosphocreatine; $\mathrm{Pi}=$ inorganic phosphate; $\mathrm{tChol}=$ total choline

W ith an estimated lifetime prevalence of up to $5.1 \%,{ }^{1}$ bipolar disorder (BD) is a disabling and often fatal brain disease characterized by recurrent episodes of depression and mania. In pediatric $\mathrm{BD}$, the rate of attempted suicide is 40 times that of healthy adolescents, ${ }^{2}$ and BD is the diagnosis imparting the greatest risk for completed suicide. ${ }^{3}$ Adding to the morbidity and mortality imposed on patients and their families, the annual economic burden of BD in the United States is at least $\$ 151$ billion. ${ }^{4}$ Despite decades of research, the underlying pathophysiology of BD across the life span is yet to be elucidated.,

The neurobiology of pediatric BD is of particular interest because up to $65 \%$ of patients with BD experience its onset before 19 years of age. ${ }^{7,8}$ Adolescence is the peak period for the first episode of mania, ${ }^{9}$ the mood state that defines the illness. In fact, the World Health Organization ranks BD as the fourth most disabling disease worldwide in persons between 10 and 24 years of age. ${ }^{10}$

Received May 29, 2013; accepted after revision October 7.

From The Brain Institute (D.G.K., T.L.H., X.F.S., Y.H.S., A.P.P., R.S.H., L.N.F., P.F.R), University of Utah, Salt Lake City, Utah; Departments of Psychiatry (D.G.K., X.F.S., Y.H.S., P.F.R.) and Radiology (A.P.P.), University of Utah School of Medicine, Salt Lake City, Utah; Veterans Integrated Service Network 19 Mental Illness Research (P.F.R.), Education and Clinical Center, VA Salt Lake City Health Care System, Salt Lake City, Utah; and Department of Psychiatry (T.S.K.), Catholic University of Korea Graduate School of Medicine, Seoul, Republic of Korea.

Please address correspondence to Douglas G. Kondo, MD, University of Utah, 383 Colorow Dr, Salt Lake City, Utah 84108; e-mail: doug.kondo@hsc.utah.edu

- Indicates open access to non-subscribers at www.ajnr.org

http://dx.doi.org/10.3174/ajnr.A3844
Leverich et $\mathrm{al}^{11}$ found that childhood-onset BD is associated with a delay of first treatment of $>16$ years. Expert consensus has identified the improved definition and diagnosis of pediatric BD, based on its underlying pathophysiology, as a critical barrier to progress in the field. ${ }^{12}$ The National Institute of Mental Health Strategic Plan ${ }^{13}$ and A Research Agenda for DSM- $V^{14,15}$ both advocate attempts to discover neuroimaging biomarkers of $\mathrm{BD}$. Thus, neuroimaging has an important role to play in translational research in pediatric $\mathrm{BD} .{ }^{16-18}$

Converging lines of evidence implicate 2 related systems in the pathophysiology of BD: 1) alterations in glutamatergic neurotransmission, ${ }^{19-21}$ and 2) cerebral mitochondrial dysfunction. ${ }^{22-24}$ They are interdependent because $>80 \%$ of all synapses are glutamatergic ${ }^{25}$ and approximately $85 \%$ of the energy derived from glucose in the brain is used to support glutamatergic neurotransmission and the conversion of glutamate (Glu) to glutamine (Gln). ${ }^{26,27}$

Mood-related alterations in cerebral bioenergetics would presumably have an impact on the glutamate system. Support for this is provided by the fact that inhibition of mitochondrial respiratory chain complexes I, III, and IV in an animal model of depression is reversed by administration of the N-methyl-D-aspartate glutamate receptor antagonist ketamine, ${ }^{28}$ a novel intervention for refractory BD. ${ }^{29,30} \mathrm{MR}$ spectroscopy is a neuroimaging method capable of noninvasive interrogation of specific brain metabolites in vivo. Because it allows measurement of the chemical status of specific brain regions, MR spectroscopy is one potential method for establishing quantitative correlates of illness 
and treatment response in psychiatric conditions such as BD. ${ }^{31,32}$ Accordingly, MR spectroscopy has been used extensively in $\mathrm{BD}$ research to study both the glutamate system and brain bioenergetics. Two systematic reviews ${ }^{33,34}$ and 1 meta-analysis ${ }^{35}$ have each concluded that MR spectroscopy studies provide convincing evidence for glutamatergic abnormalities in BD. As reviewed by Stork and Renshaw, ${ }^{36}$ the MR spectroscopy literature in BD also provides consistent support for mitochondrial dysfunction. The promising nature of these findings has led to the conjecture that MR spectroscopy studies may represent "a pathway to diagnosis, novel therapeutics, and personalized medicine" in mood disorders. ${ }^{37}$

There is an urgent need for translational pediatric BD research, for the reasons enumerated above and because the data suggest that juvenile $\mathrm{BD}$ is continuous with adult $\mathrm{BD} \cdot{ }^{38-40}$ The MR spectroscopy literature in pediatric major depressive disorder was recently reviewed, ${ }^{41}$ but a review of MR spectroscopy studies of child and adolescent BD is lacking. The purpose of this article is to provide a companion review in pediatric $\mathrm{BD}$, with particular attention paid to evidence for alterations in the glutamatergic system and mitochondrial dysfunction, and to discuss opportunities for further study.

\section{MR Spectroscopy Measures Relevant to Bipolar Disorder}

A technical description of MR spectroscopy methods for data acquisition and analysis is beyond the scope of this article, but excellent technical reviews are available. ${ }^{42,43} \mathrm{MR}$ spectroscopy can be used to study a range of atomic nuclei that possess magnetic properties, including hydrogen $\left({ }^{1} \mathrm{H}\right)$, phosphorus $\left({ }^{31} \mathrm{P}\right)$, lithium $\left({ }^{7} \mathrm{Li}\right)$, fluorine $\left({ }^{19} \mathrm{~F}\right)$, and carbon $\left({ }^{13} \mathrm{C}\right) .{ }^{31}$ To date, the published pediatric BD literature has largely focused on 2 of these: ${ }^{1} \mathrm{H}$ and ${ }^{31} \mathrm{P}$.

'H-MR Spectroscopy. The most common spectroscopic imaging method used in BD research is ${ }^{\mathbf{1}} \mathrm{H}$-MR spectroscopy because the scans can be obtained on standard low-field clinical systems. Glutamatergic ${ }^{1} \mathrm{H}-\mathrm{MR}$ spectroscopy metabolites include Glu, Gln, $\gamma$-aminobutyric acid (GABA) and $N$-acetyl aspartylglutamate. ${ }^{44}$ At the magnetic field strengths used in clinical research, separation of the Glu and Gln resonance is unreliable ${ }^{42}$; however their combined peak (Glx) can be accurately quantified and therefore is most commonly reported. Although by convention Glx is defined as Glu + Gln, GABA may also contribute to the total Glx signal. ${ }^{45}$ However, when conventional MR spectroscopy methods are used, the contribution of GABA to Glx is considered very small. ${ }^{46}$

Significant findings in ${ }^{\mathbf{1}} \mathrm{H}-\mathrm{MR}$ spectroscopy measures considered indicators of mitochondrial dysfunction in $\mathrm{BD}$ include the following: decreased NAA, decreased total creatine, increased total choline (tChol), increased Glx, and increased mIns. ${ }^{36} \mathrm{NAA}$ is synthesized inside neuronal mitochondria from L-aspartate + acetyl coenzyme A by the enzyme L-aspartate- $\mathrm{N}$-acetyl transferase in an energy-dependent process, suggesting that decreased NAA concentrations are consistent with impaired mitochondrial bioenergetics. ${ }^{36,47}$ The concentration of NAA by in vivo ${ }^{1} \mathrm{H}-\mathrm{MR}$ spectroscopy methods is consistently higher than that found by careful ${ }^{1} \mathrm{H}$-nuclear MR analysis of freeze-clamped animal brain tissue, suggesting additional contributions to the "NAA" in vivo peak. ${ }^{48}$ The total creatine peak is composed of phosphocreatine

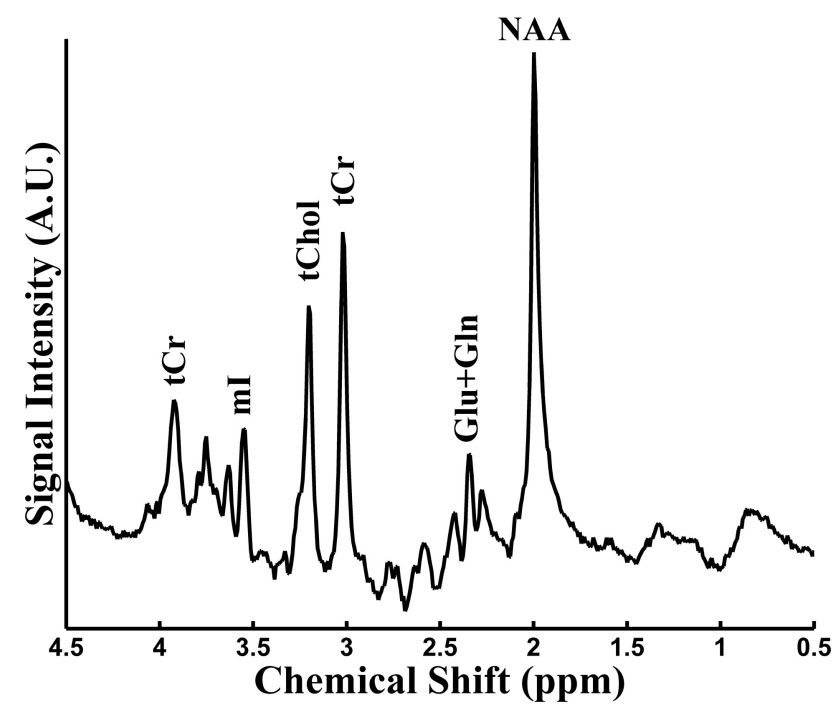

FIG 1. Representative proton-1 MR spectroscopy ('H-MRS) spectrum acquired with parameters TR/TE $=2000 / 31 \mathrm{~ms}$ on a 3T MR imaging scanner.

(PCr), a temporal and spatial buffer of adenosine triphosphate (ATP), and creatine $(\mathrm{PCr}+\mathrm{Cre})$. tChol is a trimethylamine peak that is composed of phosphocholine, a membrane phospholipid precursor; glycerophosphocholine, a membrane phospholipid breakdown product; and choline, acetylcholine, carnitine, and acetyl-L-carnitine. The replicated finding of increased tChol in adult $\mathrm{BD}$ is hypothesized to be due to increased phospholipid turnover resulting from mitochondrial dysfunction. ${ }^{36}$ The Glx peak contains contributions from glutamate, glutamine, and $\gamma$-aminobutyric acid. The largest contributors to the Glu resonance are Glu in metabolic pathways and, to a much lesser degree, the neurotransmitter Glu. Increased Glx in BD is hypothesized to reflect Glu-induced neuronal hyperactivation, ${ }^{36}$ which places abnormally large demands on neuronal and glial energy metabolism. ${ }^{46}$

Notably, the classic medication lithium has a significant normalizing effect on Glx in $\mathrm{BD} .{ }^{49}$ The mIns resonance consists primarily ( $>95 \%$ ) of the cyclic sugar alcohol mIns, with minor contributions from inositol sugar phosphate compounds and glycine. ${ }^{50}$ The relevance of mIns to BD stems from its status as a potential indicator of altered membrane metabolism resulting from mitochondrial dysfunction ${ }^{36}$ and the fact that a decrease in mIns is associated with administration of the BD medication lithium. ${ }^{36}$ A representative ${ }^{1} \mathrm{H}-\mathrm{MR}$ spectroscopy spectrum is shown in Fig 1.

${ }^{31} \mathrm{P}$ MR Spectroscopy. Another MR spectroscopy technique used in $\mathrm{BD}$ research is ${ }^{31} \mathrm{P}-\mathrm{MR}$ spectroscopy, which requires specialized hardware and software, such as a dual-tuned ${ }^{1} \mathrm{H}_{-}{ }^{31} \mathrm{P}$ radiofrequency coil, a broadband radio-frequency power amplifier, and customized pulse sequences. Investigator experience with ${ }^{31} \mathrm{P}-\mathrm{MR}$ spectroscopy pulse-sequence design and data processing/ analysis is also essential because MR imaging system manufacturers do not typically supply these tools. Yet ${ }^{31} \mathrm{P}-\mathrm{MR}$ spectroscopy may provide unique insights into BD neurobiology because it is a validated method for in vivo measurement of the ultimate mitochondrial process: ATP synthesis. ${ }^{51}$ Few ${ }^{31} \mathrm{P}-\mathrm{MR}$ spectroscopy 


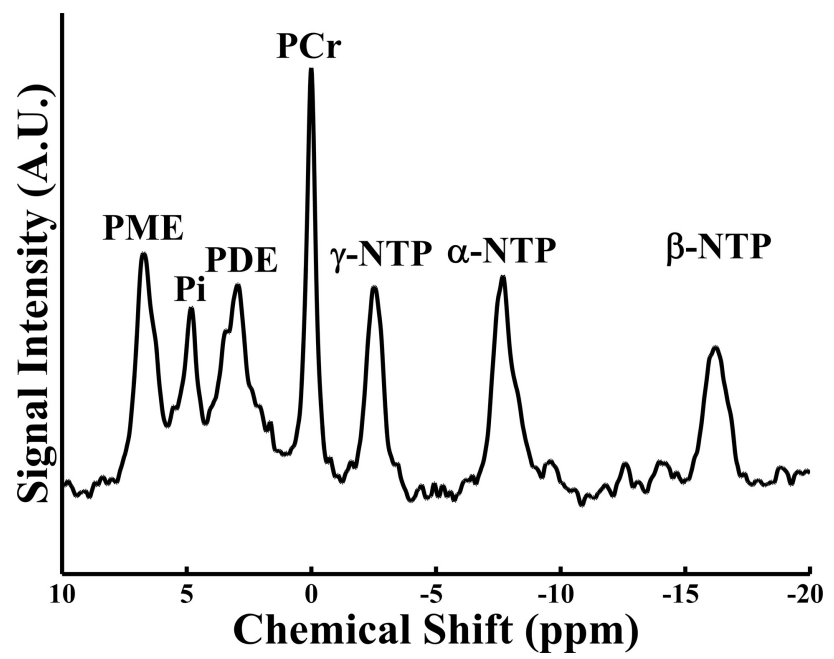

FIG 2. Representative phosphorus $31 \mathrm{MR}$ spectroscopy ( ${ }^{31} \mathrm{P}-\mathrm{MRS}$ ) spectrum acquired without proton decoupling on a 3T MR imaging scanner.

studies of adult BD have been reported, ${ }^{52}$ and to date, there are just 3 published ${ }^{31} \mathrm{P}-\mathrm{MR}$ spectroscopy investigations in the pediatric $\mathrm{BD}$ literature. ${ }^{53-55}{ }^{31} \mathrm{P}-\mathrm{MR}$ spectroscopy measures relevant to mitochondrial function include phosphomonoesters, phosphodiesters, $\beta$-nucleoside triphosphate, $\mathrm{PCr}$, inorganic phosphate (Pi), and intracellular $\mathrm{pH}^{52}$ The phosphomonoesters signal contains contributions from the membrane precursors phosphoethanolamine and phosphocholine, in addition to sugar and inositol phosphates. ${ }^{36}$ Phosphomonoesters are the building block precursors of neuronal membrane phospholipids. Both increased and decreased phosphomonoesters has been observed in studies of BD; thus, changes in the phosphomonoesters resonance may be state-dependent - with increased phosphomonoesters in depression and mania reflecting increased membrane phospholipid turnover, with decreased phosphomonoesters in subjects with euthymic BD possibly reflecting an opposite quiescence. ${ }^{36}$

The phosphodiester signal, made up of contributions from glycerophosphocholine, glycerophosphoethanolamine, and mobile phospholipids, represents the breakdown products of phospholipid membranes. ${ }^{52} \mathrm{PCr}$ is the buffer storage form of ATP and serves as the substrate reservoir for the creatine kinase reaction. ${ }^{56}$ In the mitochondria, this reaction reversibly converts $\mathrm{PCr}$ into ATP + creatine in a 1:1 molar ratio. ${ }^{57,58}$ Neuronal energy demands are met through a shift in reaction equilibrium, which is designed to maintain constant ATP concentrations. ${ }^{59-61} \beta$-nucleoside triphosphate predominately measures $\beta$-ATP levels and is, therefore, used as a proxy measure of relative ATP concentrations. $\mathrm{Pi}$ and adenosine diphosphate are the products of the ATP hydrolysis reaction and are released when ATP is consumed. Intracellular $\mathrm{pH}$ can be calculated by using a modified Henderson-Hasselbalch equation and the resonance Pi relative to $\mathrm{PCr} .{ }^{62}$ Figure 2 presents a representative ${ }^{31} \mathrm{P}-\mathrm{MR}$ spectroscopy spectrum.

\section{MATERIALS AND METHODS}

\section{Search Strategy}

A computer-assisted literature search by using PubMed and MEDLINE data bases of the National Library of Medicine was conducted to identify reports focusing on pediatric BD samples studied with MR spectroscopy. The following terms were included in the search: "MR spectroscopy," "bipolar disorder," "pediatric or child or adolescent or juvenile or early-onset." A backward search of bibliographic references from the identified references was performed to ensure inclusion of relevant articles; a forward citation search for identified studies was also performed. We also included reports from MR spectroscopy studies of at-risk youth who were the offspring of parents with BD and subjects with severe mood dysregulation, ${ }^{63}$ also known as disruptive mood dysregulation disorder, ${ }^{64}$ a new mental illness of childhood published in the Diagnostic and Statistical Manual of Mental Disorders, 5th ed, ${ }^{65}$ the diagnostic manual for US psychiatrists, in May 2013. All relevant articles published in English were included, and due to the small number of studies, no MR spectroscopy methodologic exclusion criteria were applied.

\section{RESULTS}

\section{Overview of the Literature}

The literature searches yielded 55 citations, of which 26 contained original neuroimaging acquired from subjects younger than 18 years of age. The sample characteristics, scanning acquisition methods, voxel location, and MR spectroscopy metabolite results are presented in Tables 1-4, and the key findings related to glutamatergic and mitochondrial function are summarized below. In addition to the modest number of reports and diversity of study methods and samples, this literature is in its infancy: The first MR spectroscopy study of pediatric BD was published in 2000. Despite this, the investigations conducted to date point to numerous important directions for further study.

\section{Cross-Sectional MR Spectroscopy Studies of Pediatric BD}

Cross-Sectional Studies of the Glutamate System. A summary of the cross-sectional MR spectroscopy studies comparing patients with pediatric BD versus healthy controls ( $\mathrm{HC}$ ) is shown in Table 1. Castillo et al ${ }^{66}$ were the first to study juvenile patients with BD and controls in 2000, reporting that patients with BD showed elevated Glx in the bilateral frontal lobes and basal ganglia. In a cross-sectional study of stably medicated pediatric patients with BD versus patients with mania, Glx was decreased in mania; this finding, the authors noted, could represent anterior cingulate cortex (ACC) hypometabolism. ${ }^{67}$ In another study, decreased ACC Gln was found in pediatric patients with manic BD, compared with both controls and stably medicated patients, ${ }^{68}$ while there were no differences in Glu.

Cross-Sectional Studies of Mitochondrial Function. The frontal lobes have been the subject of numerous case-control studies in pediatric $\mathrm{BD}$, with several investigators reporting decreased NAA concentrations in subjects with pediatric BD compared with controls. ${ }^{69-73}$ In one report whose findings were in the opposing direction, Patel et $\mathrm{al}^{74}$ reported increased NAA in the ACC in patients with pediatric BD depression. Two studies reported increased mIns in pediatric $\mathrm{BD}$, compared with both $\mathrm{HC}^{74}$ and intermittent explosive disorder. ${ }^{75}$ One study of pediatric mania found reduced tChol levels compared with $\mathrm{HC},{ }^{75}$ while a study of pediatric BD depression found an increase in tChol. ${ }^{74}$

As noted above, 3 recent studies of pediatric BD used ${ }^{31} \mathrm{P}-\mathrm{MR}$ 


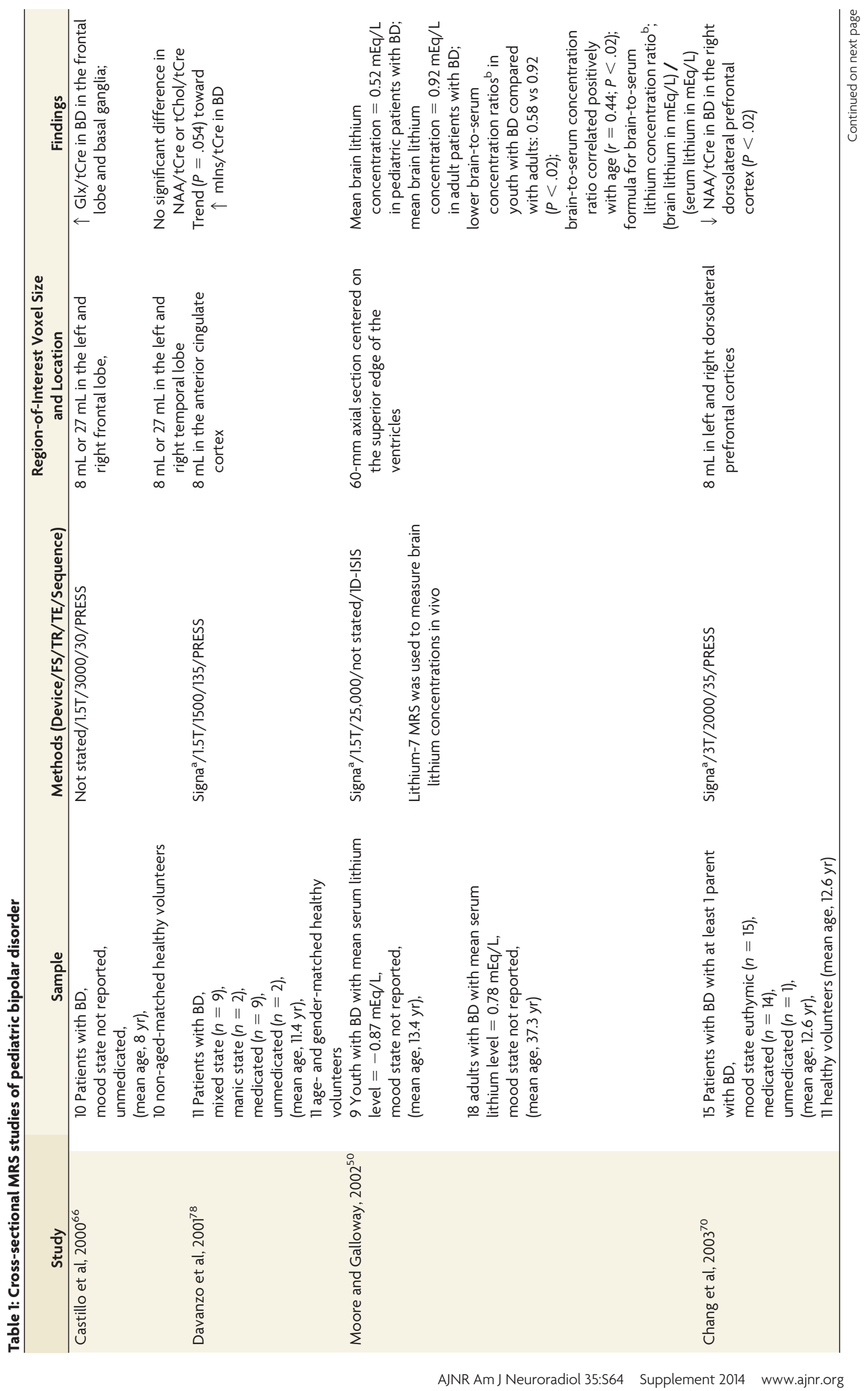




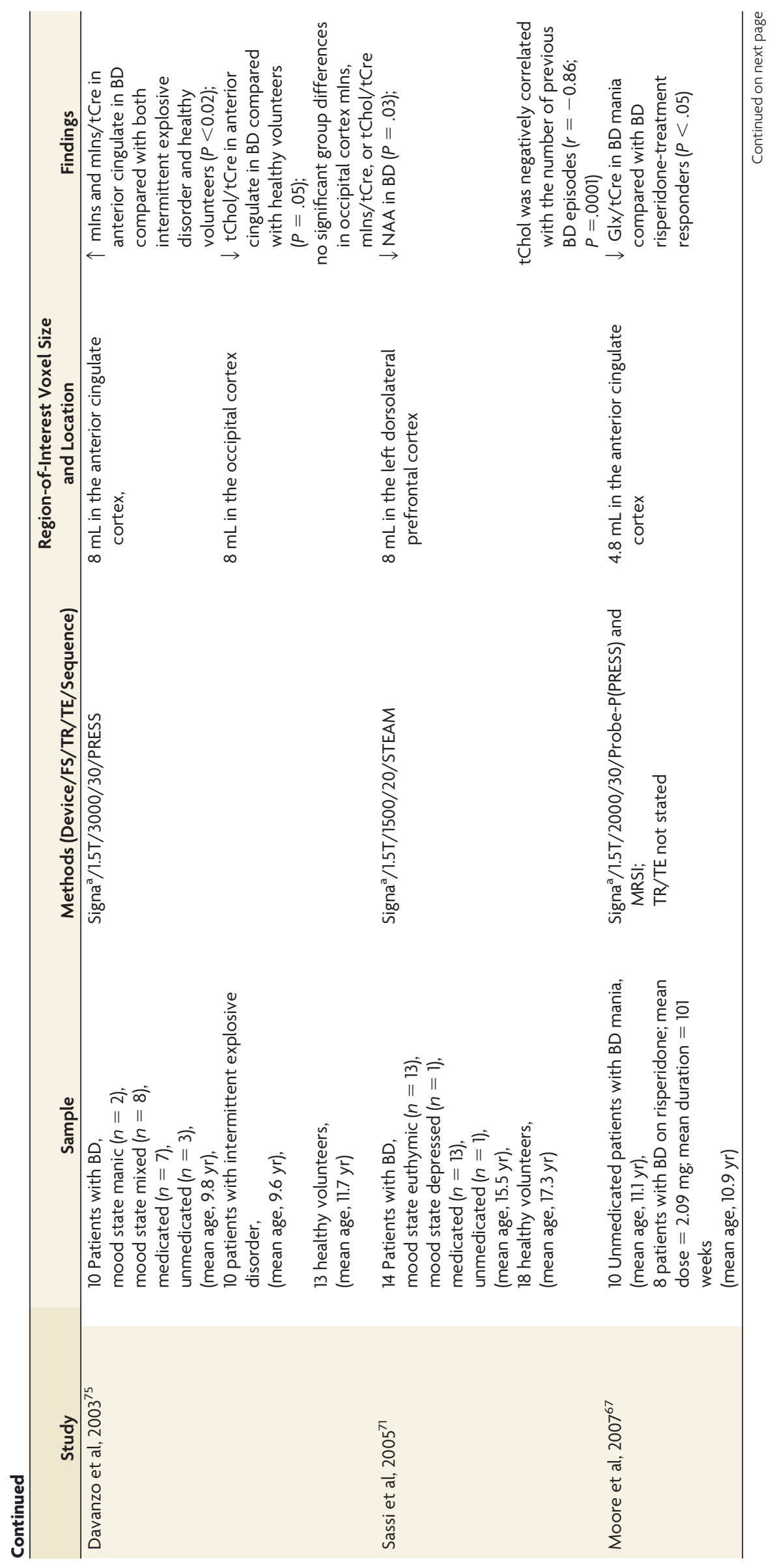

S68 Kondo Supplement 2014 www.ajnr.org 


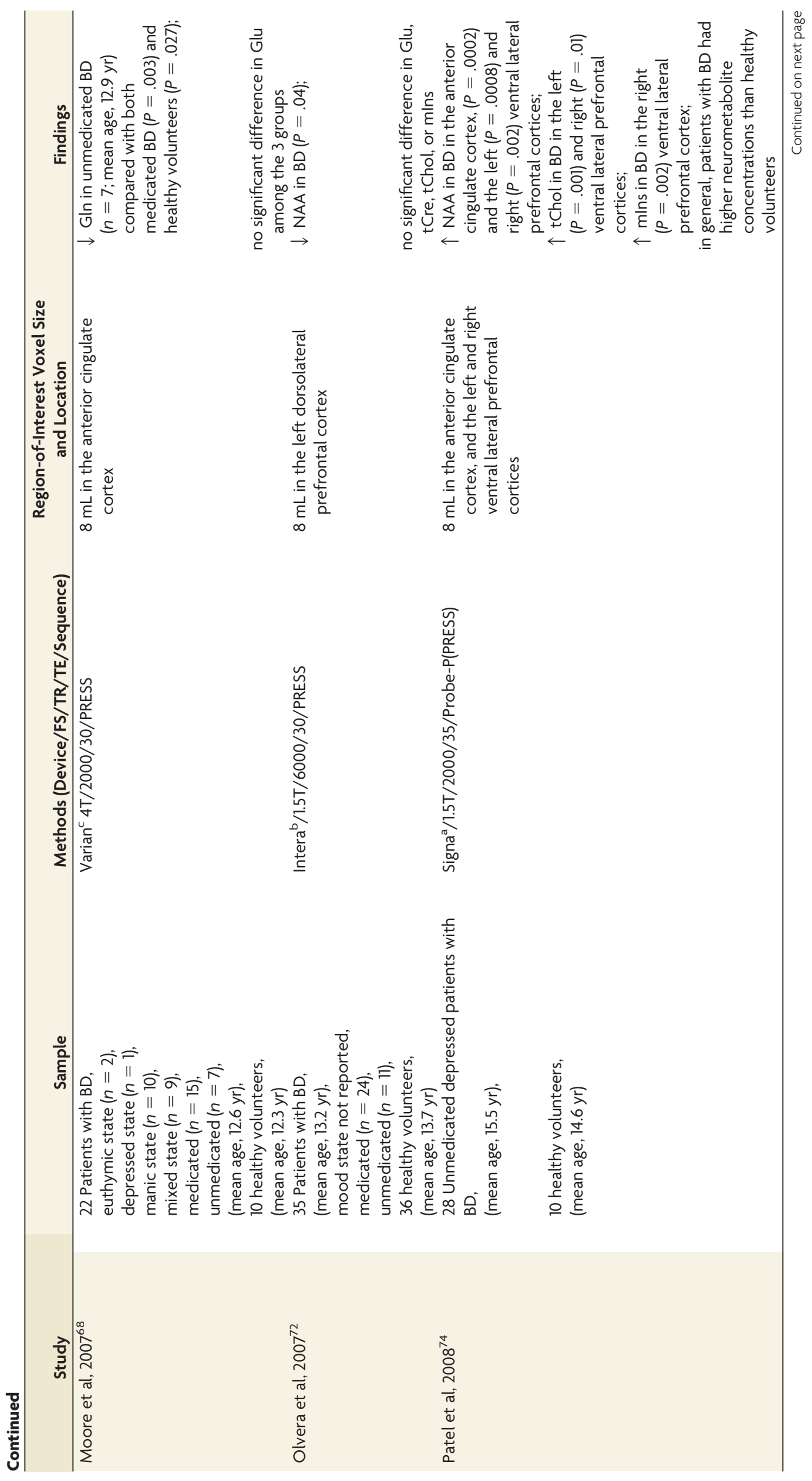




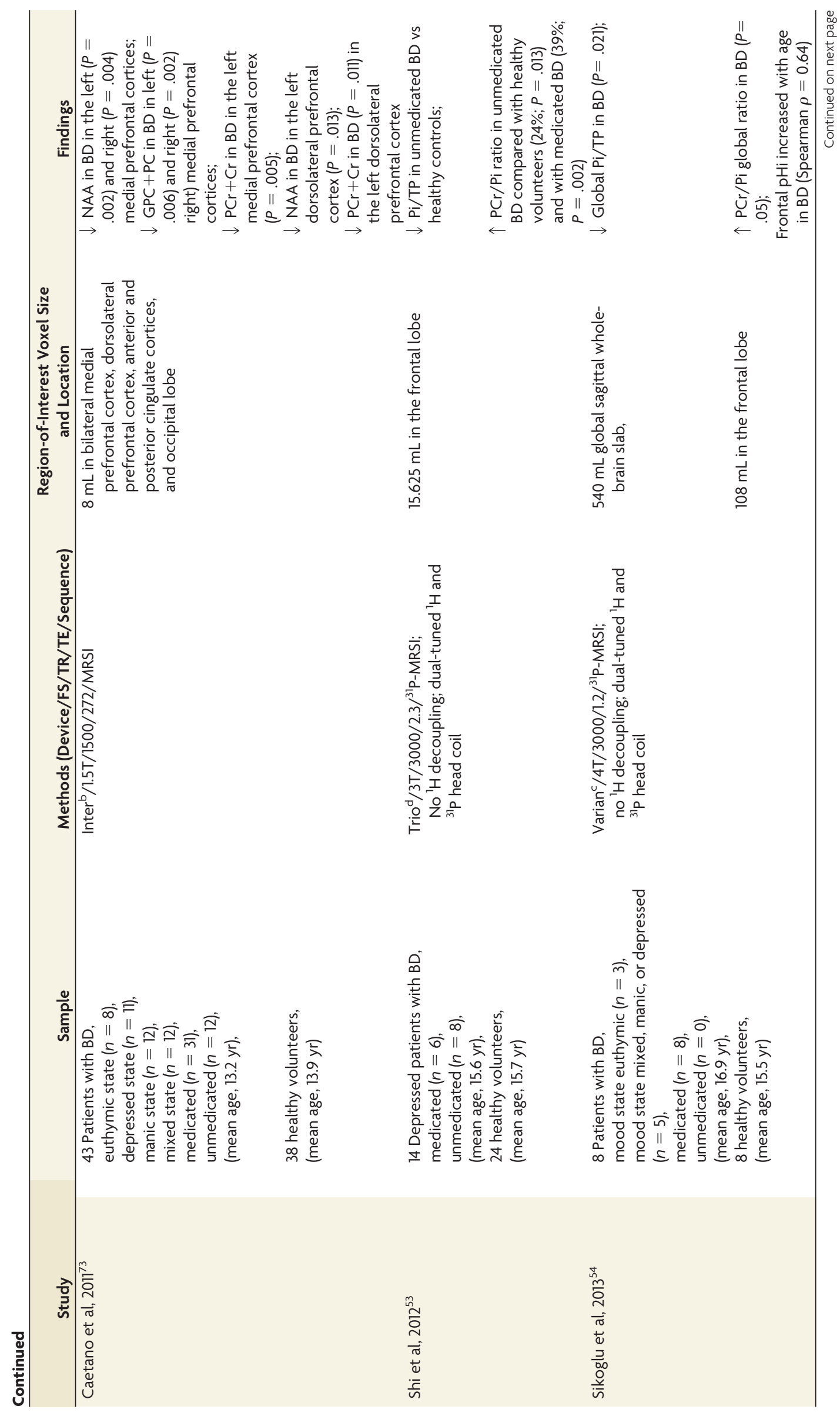

S70 Kondo Supplement 2014 www.ajnr.org 


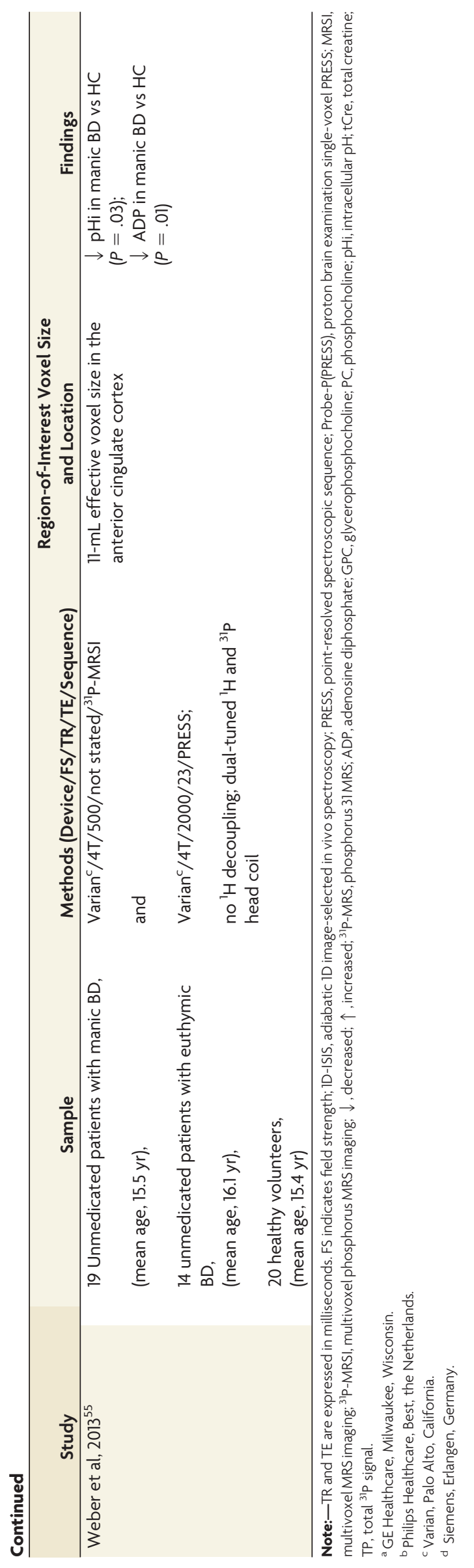

spectroscopy to study cerebral energy metabolism: Shi et $\mathrm{al}^{53}$ focused on the frontal lobe, Sikoglu et $\mathrm{al}^{54}$ reported global or "whole brain" findings, and Weber et $\mathrm{al}^{55}$ interrogated the ACC. Most interesting, none of the studies reported a significant difference between $\mathrm{BD}$ and $\mathrm{HC}$ in $\beta$-nucleoside triphosphate (a proxy measure for ATP), but 2 investigators reported a significant decrease in $\mathrm{Pi}$ and an increased $\mathrm{PCr} / \mathrm{Pi}$ ratio, ${ }^{53,54}$ neither of which has been reported in studies of adult $\mathrm{BD}$. In the most recent ${ }^{31} \mathrm{P}-\mathrm{MR}$ spectroscopy study of pediatric $\mathrm{BD}$, manic subjects had reduced intracellular $\mathrm{pH}$ and lower adenosine diphosphate concentrations in the ACC. ${ }^{55}$

\section{Longitudinal Treatment MR Spectroscopy Studies of Pediatric BD and High-Risk Samples}

Longitudinal Studies of the Glutamate System. Strawn et $\mathrm{al}^{76}$ treated pediatric patients with BD in a manic or mixed episode with valproic acid and performed ${ }^{1} \mathrm{H}-\mathrm{MR}$ spectroscopy at baseline, day 7 , and day 28 (Table 2). In subjects who achieved clinical remission with valproic acid, the investigators found a decreased baseline Glx and a correlation between a change in the Young Mania Rating Scale ${ }^{77}$ scores and decreased Glu in the left ventrolateral prefrontal cortex. ${ }^{76}$

Longitudinal Studies of Mitochondrial Function. Repeated-measures MR spectroscopy studies of treatment response have been conducted in pediatric BD and in high-risk samples of children with a parent with BD. Davanzo et $\mathrm{al}^{78}$ treated pediatric inpatients with manic BD with lithium and found that decreased mIns was associated with treatment, an effect that was stronger in treatment responders. Patel et $\mathrm{al}^{79}$ treated adolescents with BD depression with lithium and found that mIns concentrations did not significantly change from baseline, though pretreatment cortical mIns was significantly lower in patients who achieved remission. The same investigators later reported a significant decrease in NAA levels in response to treatment with lithium. ${ }^{80}$ DelBello et al ${ }^{81}$ treated pediatric patients with mania with olanzapine and found that increased tChol was associated with treatment; in addition, treatment remitters demonstrated increased NAA while nonremitters showed a decrease in NAA. Chang et al ${ }^{82}$ randomized subjects with pediatric BD depression to quetiapine or placebo and found that decreased mIns levels were associated with a positive treatment response. One repeated-measures MR spectroscopy study has been performed with a high-risk sample of youth with subsyndromal mood symptoms and at least 1 parent with BD: Chang et $\mathrm{al}^{83}$ found no significant alterations in NAA, tChol, or mIns associated with valproic acid treatment. However, a large effect size was noted for decreased posttreatment NAA in the right dorsolateral prefrontal cortex. ${ }^{83}$

\section{Cross-Sectional MR Spectroscopy Studies of Youth at Risk for BD}

Cecil et $\mathrm{al}^{69}$ conducted a study of mood-disordered children with a familial risk for BD and found increased mIns and decreased NAA in the high-risk subjects compared with HC (Table 3). Gallelli et $\mathrm{al}^{84}$ studied children of parents with BD in 3 groups: those with $\mathrm{BD}$, those with subsyndromal BD symptoms, and HC. Measuring NAA, mIns, and tChol, the investigators found no signifi- 


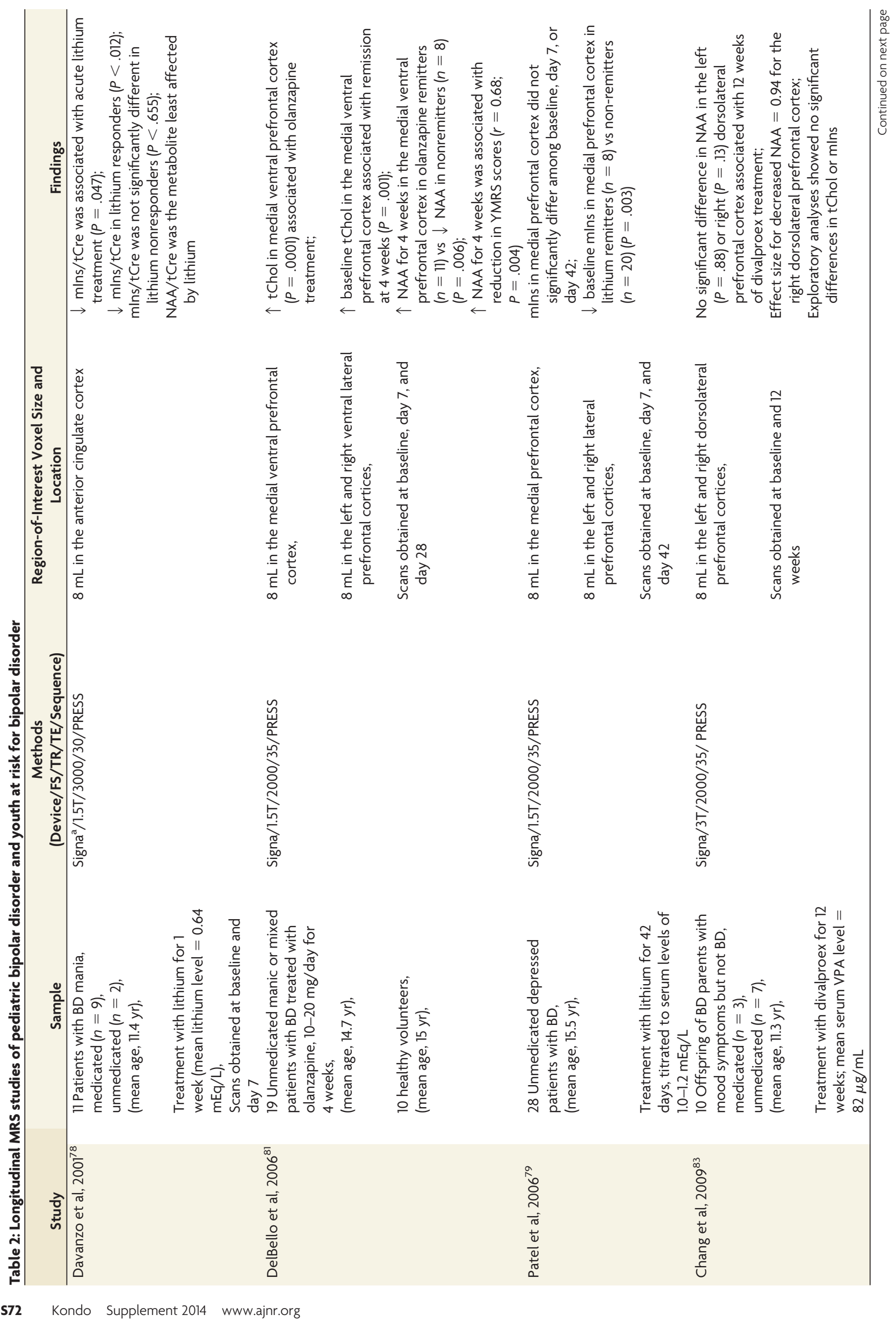




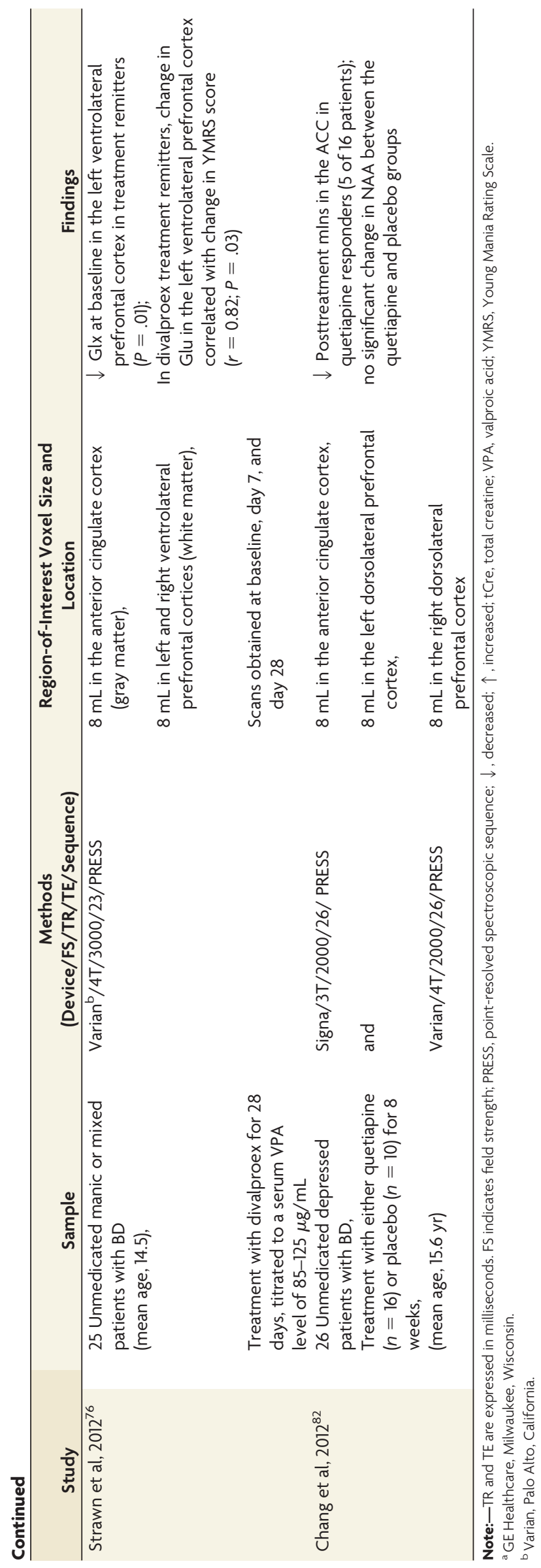

cant between-group differences. Singh et $\mathrm{al}^{85}$ studied an at-risk sample of offspring of parents with BD, focusing first on the ACC and then on the cerebellar vermis. ${ }^{86}$ In the ACC, the authors found decreased absolute Glu concentrations in $\mathrm{BD}$ compared with both $\mathrm{HC}$ and offspring with subsyndromal BD symptoms. ${ }^{85}$ Then, studying at-risk offspring without BD and HC, Singh et a ${ }^{86}$ reported decreased cerebellar mIns and tChol. Finally, Wozniak et $\mathrm{al}^{87}$ measured ACC Glu in children with at least 1 parent with $\mathrm{BD}$, dividing their sample into children with high-versus-low scores on a Child Behavior Checklist ${ }^{88}$ profile proposed as a correlate of pediatric BD. ${ }^{89,90}$ No group differences in ACC Glu were found, but in the high-score group, there was a positive correlation between Glu levels and Child Behavior Checklist profile scores. ${ }^{87}$

\section{Cross-Sectional and Repeated-Measures MR Spectroscopy Studies of Severe Mood Dysregulation}

The publication of the Diagnostic and Statistical Manual of Mental Disorders, 5th ed ${ }^{65}$ in May 2013 introduced disruptive mood dysregulation disorder as a new mood disorder of childhood (Table 4). Designed to differentiate children who present with severe, nonepisodic irritability from those with $\mathrm{BD},{ }^{91}$ disruptive mood dysregulation disorder is closely related to the severe mood dysregulation syndrome defined by Leibenluft ${ }^{63}$ and Leibenluft et al. ${ }^{92}$ Dickstein et $\mathrm{al}^{93}$ conducted a series of prescient MR spectroscopy investigations of severe mood dysregulation. In a case-control study, the investigators used ${ }^{1} \mathrm{H}-\mathrm{MR}$ spectroscopy to interrogate the frontal, temporal, and parietal cortices in severe mood dysregulation versus $\mathrm{HC}$; their main finding was reduced mIns in the temporal cortex, though female subjects with severe mood dysregulation showed trends toward increased temporal tCr and Glx. The authors then conducted a randomized controlled trial of lithium in severe mood dysregulation, selecting this intervention on the basis of its potential effects on irritability, aggression, and neurometabolism. ${ }^{94}$ MR spectroscopy scans were acquired at baseline and repeated following 6 weeks of treatment with lithium or a placebo. A significant treatment Group $\times$ Time interaction was found for parieto-occipital Glx, which increased in the lithium group and decreased in placebo group. ${ }^{94}$

\section{DISCUSSION}

Pediatric BD is a prevalent and disabling illness, for which progress in timely diagnosis and effective treatment is urgently needed. Research in psychiatry is increasingly focused on biomarker discovery, ${ }^{95,96}$ and a consensus is emerging that MR neuroimaging investigations, ${ }^{16}$ including multimodal approaches that include MR spectroscopy, ${ }^{17}$ offer significant promise in elucidating the pathophysiology of BD. ${ }^{97}$

Findings Related to the Glutamate System in Pediatric BD It has been proposed that MR spectroscopy studies of the glutamate system may hold the key to elucidating the pathophysiology of $\mathrm{BD}$ and to identifying novel treatment interventions. ${ }^{37}$ In adults, a consistent pattern has emerged in meta-analyses of the MR spectroscopy mood disorder literature: increased cerebral Glx levels in $\mathrm{BD}^{33,35}$ and decreased Glx in major depressive disorder. ${ }^{33,98}$ In comparison, there have been relatively few pediatric 


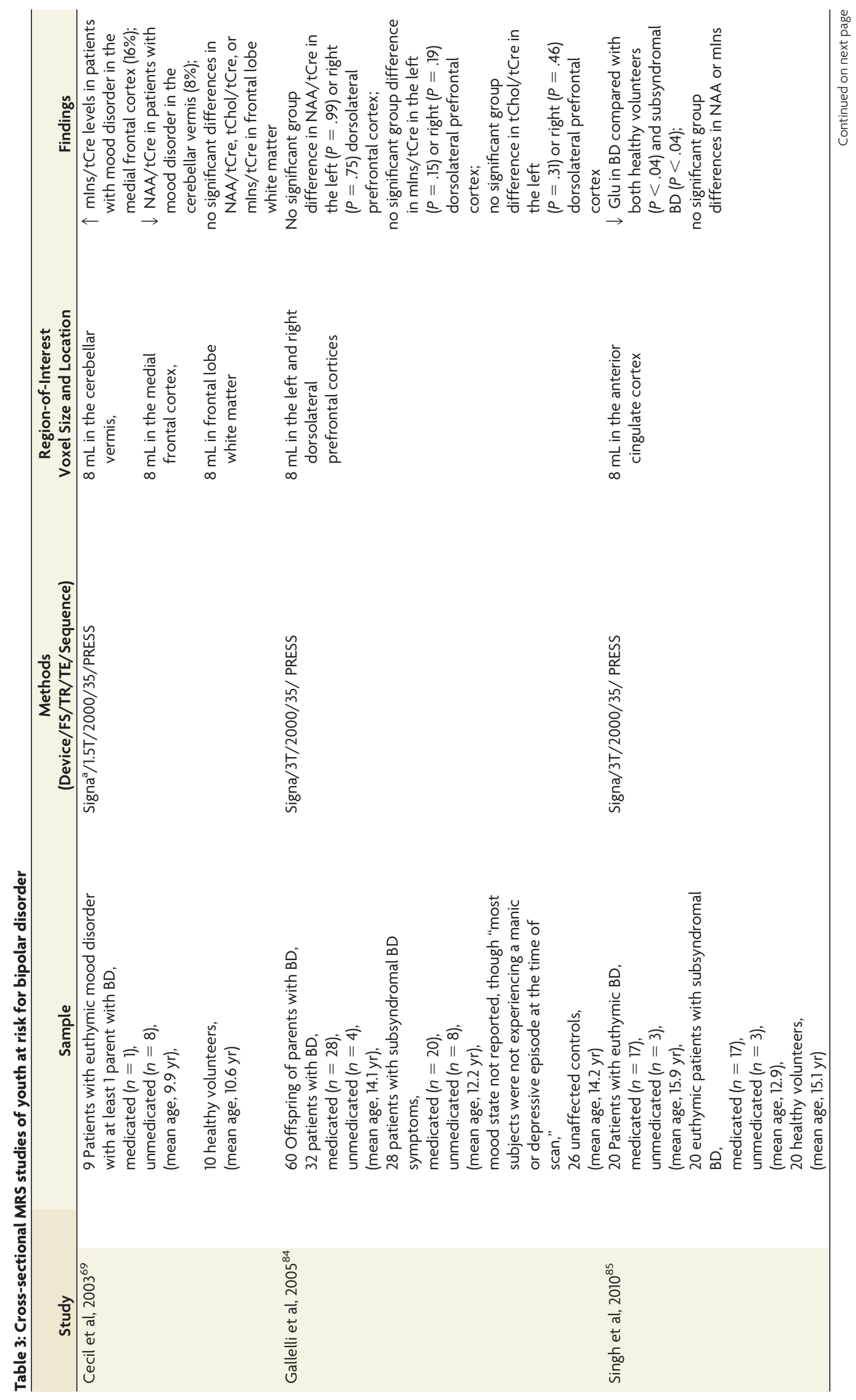

S74 Kondo Supplement 2014 www.ajnr.org 


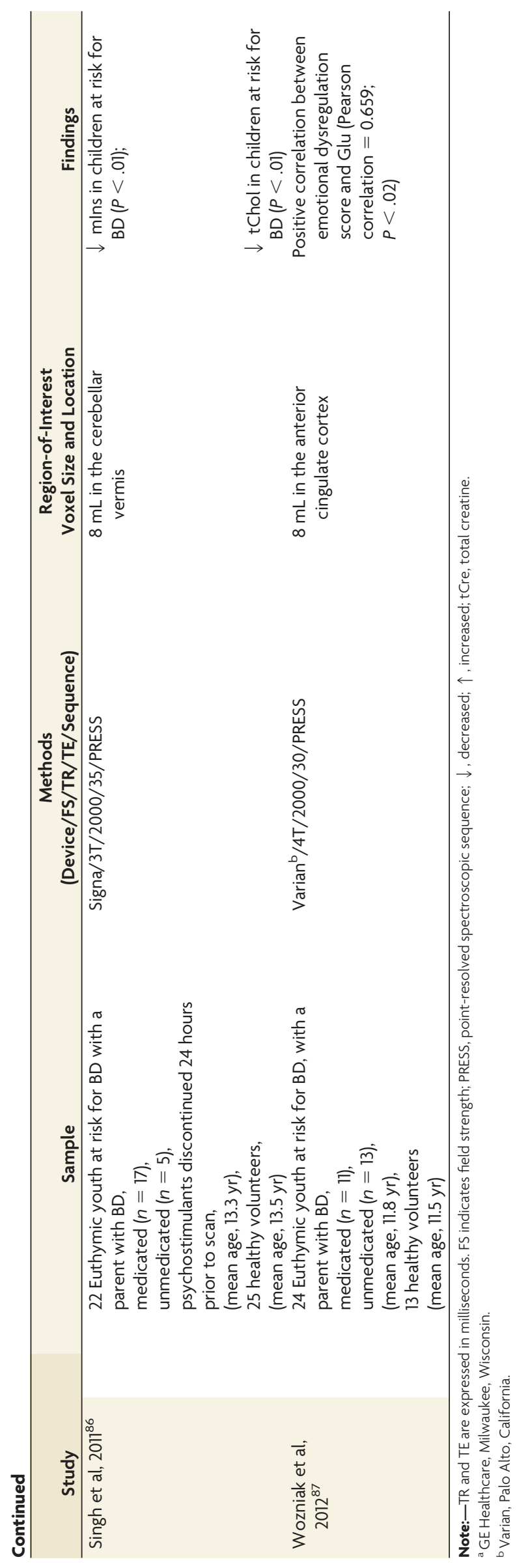

$\mathrm{BD}$ studies of the glutamate system. In line with the adult BD literature, Castillo et al ${ }^{66}$ reported elevated Glx in pediatric BD compared with HC. Moore et al ${ }^{67}$ reported decreased Glx in BD mania compared with subjects with BD stably treated with risperidone. Using high-field $4 \mathrm{~T}$ scans, these investigators were also able to parse the Gln and Glu resonances in the ACC. Most intriguing, they found decreased Gln in untreated youths with BD compared with both stably medicated patients with BD and HC. ${ }^{67}$ Taken together with the fact that there was no difference in Glu among the 3 groups, ${ }^{67}$ this finding suggests that the Gln/Glu ratio measured in adult $\mathrm{BD}$ investigations ${ }^{99,100}$ merits further study in pediatric BD. Finally, in a longitudinal valproic acid treatment study, Strawn et al found decreased baseline Glx in treatment remitters and decreases in Young Mania Rating Scale scores correlated with decreased Glu concentrations. ${ }^{76}$ The authors concluded that the predictive value of MR spectroscopy neuroimaging "may relate to a disturbance in either glutamine or GABA, or in the homeostatic equilibrium of Glu and glutamine," ${ }^{76}$ providing further support for the exploration of the Gln/Glu ratio as a potential biomarker in pediatric BD.

\section{Findings Related to Mitochondrial Dysfunction in Pediatric BD}

There are 5 reports of decreased cortical NAA concentrations in pediatric $\mathrm{BD},{ }^{69-73}$ and 1 study of adolescent $\mathrm{BD}$ depression that found increased NAA in the left ventral lateral prefrontal cortex, right ventral lateral prefrontal cortex, and ACC. ${ }^{74}$ In addition, Castillo et al ${ }^{66}$ reported no difference in cortical NAA between BD and $\mathrm{HC}$, though the study may have been limited by its sample size. Most interesting, Chang et $\mathrm{al}^{70}$ found normal NAA levels in the dorsolateral prefrontal cortex of youth at risk for BD who had not yet experienced mania, suggesting that alterations in NAA may be a marker for fully syndromal cases of in BD. ${ }^{101}$ Longitudinal studies of NAA have shown mixed results: increased prefrontal NAA in BD manic olanzapine remitters ${ }^{81}$; decreased prefrontal NAA in depressed adolescents with BD treated with lithium ${ }^{80}$; and no significant change in NAA following treatment with lithium, ${ }^{78}$ quetiapine in $\mathrm{BD}$ depression, ${ }^{82}$ or youth at risk for BD treated with valproic acid. ${ }^{83}$ While additional work will be required to confirm the role of NAA in pediatric $\mathrm{BD}$, the 5 casecontrol studies ${ }^{69-73}$ showing decreased NAA are in agreement with the findings in the adult literature.

Studies of mIns have reported an increase in pediatric BD in both the manic ${ }^{75,78}$ and depressed mood state. ${ }^{74}$ In addition, Davanzo et $\mathrm{al}^{78}$ showed that decreased ACC mIns is associated with a positive response to acute lithium treatment, a finding that is consistent with the molecular mechanism common to mood-stabilizing medications. ${ }^{102}$

To date, only three ${ }^{31} \mathrm{P}-\mathrm{MR}$ spectroscopy studies of pediatric BD have been published. Shi et $\mathrm{al}^{53}$ studied 14 depressed subjects with $\mathrm{BD}$ and $24 \mathrm{HC}$ and found that unmedicated $\mathrm{BD}$ had decreased ACC Pi compared with both HC $(17 \% ; P=.038)$ and medicated BD $(24 \% ; P=.022)$. In a study of 8 subjects with $\mathrm{BD}$ and $8 \mathrm{HC}$, Sikoglu et $\mathrm{al}^{54}$ reported that compared with $\mathrm{HC}$, subjects with BD had reduced global Pi. The relevance of Pi to mitochondrial dysfunction in $\mathrm{BD}$ may be the fact that $\mathrm{Pi}$ is a regulator of oxidative phosphorylation, the metabolic pathway for ATP 


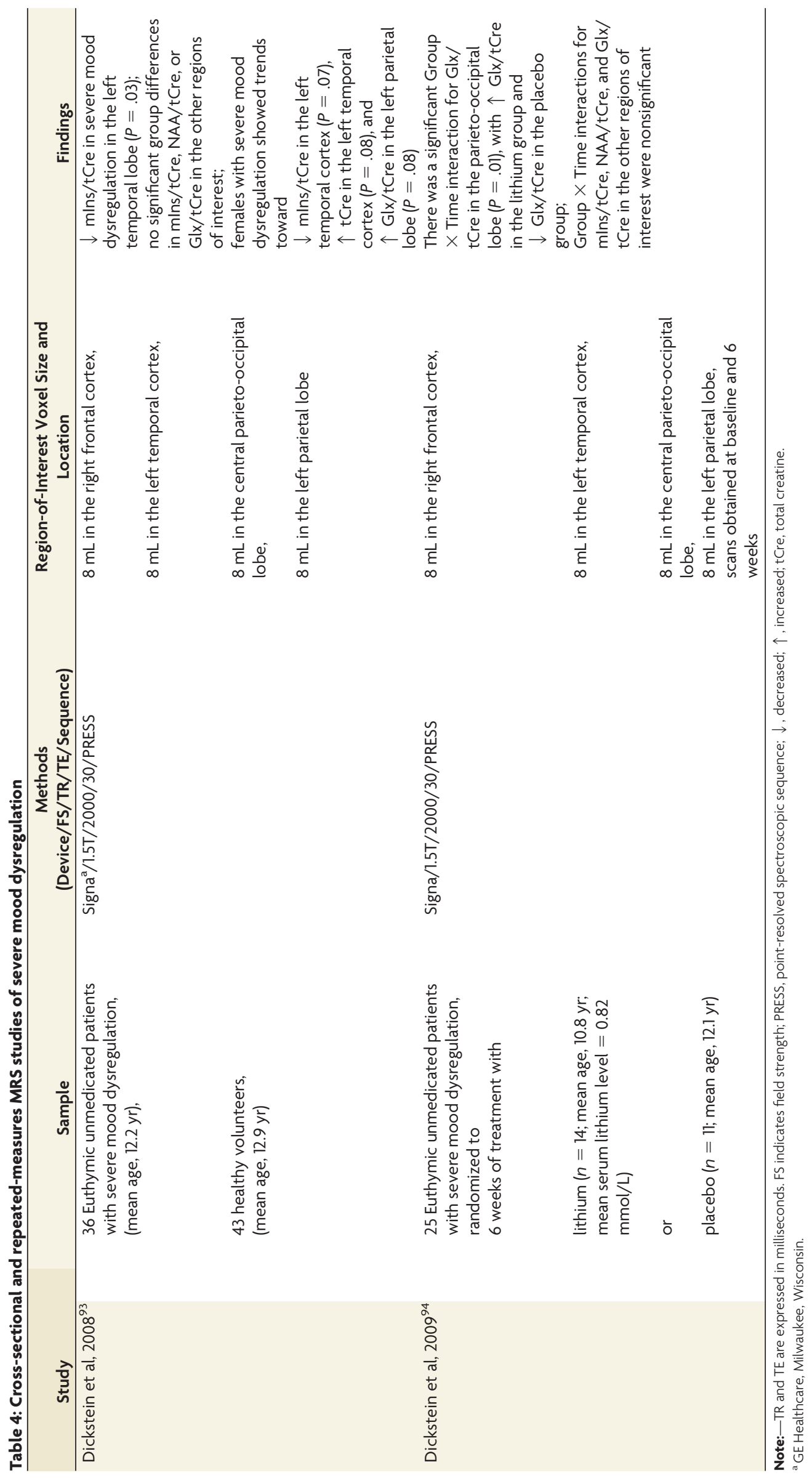


production. ${ }^{78,103}$ Furthermore, it is thought that the only Pi that is detectable by nuclear MR imaging is involved in oxidative phosphorylation. ${ }^{104,105}$ Mammalian cells in which oxidative phosphorylation is impaired can reduce the concentration of free Pi via compartmentation to the inner mitochondrial membrane, which immobilizes the phosphorus ions and renders them invisible to MR spectroscopy. ${ }^{106-108}$ In addition, Pi has a direct effect in vitro on glucose use in cortical neurons. ${ }^{109}$

It has been posited that decreased ATP consumption leads to a fall in cytosolic Pi, to a level that balances ATP synthesis and use, ${ }^{110,111}$ thus stabilizing the phosphorylation potential of the cell. ${ }^{107,108}$ Additional support for the potential relevance of $\mathrm{Pi}$ in the pathophysiology of $\mathrm{BD}$ is provided by the observation that the activity of sodium-potassium adenosine triphosphatase $(\mathrm{Na}+$ / $\mathrm{K} \pm$ ATPase), an enzyme partially regulated by $\mathrm{Pi}^{97-101,112-114}$ is altered in patients with BD. ${ }^{115}$ In the third and most recent ${ }^{31} \mathrm{P}-\mathrm{MR}$ spectroscopy study of pediatric $\mathrm{BD}$, Weber et $\mathrm{al}^{55}$ found reduced intracellular $\mathrm{pH}$ and decreased adenosine diphosphate concentrations in the ACC. These results are in line with the consistent finding of reduced intracellular $\mathrm{pH}$ in studies of adult $\mathrm{BD}^{36}$ and with the discovery of Chance et $\mathrm{al}^{116}$ that adenosine diphosphate is one of the principal controllers of oxidative metabolism.

\section{Limitations of Pediatric MR Spectroscopy Studies}

Despite the consistent difference in the glutamatergic entity Glx between patients with BD and controls found by 3 independent analyses of the adult MR spectroscopy literature ${ }^{33-35}$ and the reports of glutamatergic alterations in pediatric BD discussed here, there are uncertainties associated with MR spectroscopy measures of Glu. In the brain, Glu plays at least 3 key roles: It is the major excitatory neurotransmitter, it serves as the precursor for the major inhibitory neurotransmitter GABA, and it is involved in the synthesis of smaller metabolites, including glutathione, as well as larger peptides and proteins. ${ }^{117} \mathrm{Glu}$ is involved in a variety of metabolic pathways, including the neuronal tricarboxylic acid cycle, the astrocytic tricarboxylic acid cycle, pyruvate carboxylation, and the glutamate-glutamine cycle that links neuronal and astrocytic metabolism. ${ }^{118}$ This metabolic compartmentation leads to spatial uncertainty because Glu is present in glutamatergic neurons, GABAergic neurons, and astrocytes, in addition to extracellular spaces. The published studies of pediatric BD do not parse these multiple Glu pools in terms of either function or location.

Another important limitation of the extant pediatric BD MR spectroscopy literature is the static nature of the measurements reported. Static measures are likely to be insufficient in generating a comprehensive picture of BD pathophysiology because brain metabolism is predominantly made up of dynamic processes (ie, enzyme-catalyzed reactions and the transfer of chemical groups through metabolic pathways). Therefore, elucidation of BD etiopathogenesis may require the use of techniques capable of dynamic in vivo measures. Two examples of these that may find application in the study of BD are magnetization transfer, which can be used to measure the $\mathrm{K}_{\mathrm{f}}$ of the creatine kinase reaction, ${ }^{56}$ and dynamic ${ }^{13} \mathrm{C}$ MR spectroscopy, which has been validated as a method for studying neuronal bioenergetics and Glu neurotransmission and cycling. ${ }^{119}$

\section{Future Translational Directions in MR Spectroscopy Studies of Pediatric BD}

Improved diagnosis and treatment for pediatric $\mathrm{BD}$ are urgently needed: While the evidence suggests that pediatric bipolar illness is continuous with adult $\mathrm{BD},{ }^{38-40}$ the delay to first appropriate treatment experienced by individuals with childhood-onset $\mathrm{BD}$ averages more than 16 years. ${ }^{11}$ To date, MR spectroscopy studies of pediatric $\mathrm{BD}$ comprise a small, albeit rapidly expanding, literature. On the basis of its ability to measure neurochemical entities relevant to glutamatergic and mitochondrial function in vivo, $M R$ spectroscopy will play a vital role in future translational studies of pediatric BD diagnosis, treatment development, and personalized medicine. ${ }^{37,120}$ Cross-sectional studies are needed to determine whether MR spectroscopy can reliably distinguish pediatric BD from disorders with overlapping symptoms, such as disruptive mood dysregulation disorder, attention deficit/hyperactivity disorder, and, especially, major depressive disorder. ${ }^{121}$ Comparison with MR spectroscopy studies of normal brain development ${ }^{122}$ will shed light on the natural history of $\mathrm{BD}$ and point investigators toward opportunities for intervention. Longitudinal studies may determine the predictors of continuity with adult $\mathrm{BD}$ and whether timely treatment is capable of altering the course of $\mathrm{BD}$ in at-risk individuals. Novel study designs combining MR spectroscopy with other neuroimaging methods in a multimodal approach can be used to increase the dimensionality of the information gleaned from a study sample. ${ }^{17,123,124}$ Finally, future studies would benefit from larger sample sizes because it has been calculated that MR spectroscopy investigations require analyzable data on at least 39 affected subjects and $39 \mathrm{HC}$ to have adequate power to detect a $10 \%$ group difference in neurometabolite concentrations. ${ }^{125,126}$

Disclosures: Douglas G. Kondo—RELATED: Grant: National Alliance for Research on Schizophrenia and Depression, ${ }^{\star}$ Comments: I received a National Alliance for Research on Schizophrenia and Depression Young Investigator Award, Other: Depressive and Bipolar Alternative Treatment Foundation, Comments: I received a grant from the Depressive and Bipolar Alternative Treatment Foundation, ${ }^{*}$ UNRELATED: Employment: US Department of Veterans Affairs, ${ }^{*}$ Comments: I am employed 0.25 FTE as a VA psychiatrist. Xian-Feng Shi-RELATED: Grant: Utah Science, Technology, and Research Institute, ${ }^{*}$ Veterans Integrated Service Network 19 Mental Illness Research, Education and Clinical Center Pilot Funds. * Perry F. Renshaw—RELATED: Grant: Utah Science, Technology, and Research initiative.* *Money paid to the institution.

\section{REFERENCES}

1. Merikangas KR, Jin R, He JP, et al. Prevalence and correlates of bipolar spectrum disorder in the world mental health survey initiative. Arch Gen Psychiatry 2011;68:241-51

2. Goldstein BI. Recent progress in understanding pediatric bipolar disorder. Arch Pediatr Adolesc Med 2012;166:362-71

3. Goldstein TR, Ha W, Axelson DA, et al. Predictors of prospectively examined suicide attempts among youth with bipolar disorder. Arch Gen Psychiatry 2012;69:1113-22

4. Dilsaver SC. An estimate of the minimum economic burden of bipolar I and II disorders in the United States: 2009. I Affect Disord 2011;129:79-83

5. Newberg AR, Catapano LA, Zarate CA, et al. Neurobiology of bipolar disorder. Expert Rev Neurother 2008;8:93-110

6. DelBello MP, Adler CM, Strakowski SM. The neurophysiology of childhood and adolescent bipolar disorder. CNS Spectr 2006;11: 298-311

7. Lish JD, Dime-Meenan S, Whybrow PC, et al. The National Depressive and Manic-Depressive Association (DMDA) survey of bipolar members. J Affect Disord 1994;31:281-94

8. Perlis RH, Miyahara S, Marangell LB, et al. Long-term implications 
of early onset in bipolar disorder: data from the first 1000 participants in the systematic treatment enhancement program for bipolar disorder (STEP-BD) . Biol Psychiatry 2004;55:875-81

9. Merikangas KR, Cui L, Kattan G, et al. Mania with and without depression in a community sample of US adolescents. Arch Gen Psychiatry 2012;69:943-51

10. Gore FM, Bloem PJ, Patton GC, et al. Global burden of disease in young people aged 10-24 years: a systematic analysis. Lancet 2011;377:2093-102

11. Leverich GS, Post RM, Keck PE Jr, et al. The poor prognosis of childhood-onset bipolar disorder. J Pediatr 2007;150:485-90

12. Carlson GA, Findling RL, Post RM, et al. AACAP 2006 Research Forum-Advancing research in early-onset bipolar disorder: barriers and suggestions. J Child Adolesc Psychopharmacol 2009;19:3-12

13. Insel TR. The National Institute of Mental Health Strategic Plan. Bethesda, Maryland: US Department of Health and Human Services; 2008:37

14. Kupfer DJ, First MB, Regier DA, eds. A Research Agenda for DSM-V. Arlington, Virginia: American Psychiatric Publishing; 2002

15. Phillips ML, Vieta E. Identifying functional neuroimaging biomarkers of bipolar disorder: toward DSM-V. Schizophr Bull 2007;33: 893-904

16. Phillips ML. Coming of age? Neuroimaging biomarkers in youth. Am J Psychiatry 2010;167:4-7

17. Mayanil T, Wegbreit E, Fitzgerald J, et al. Emerging biosignature of brain function and intervention in pediatric bipolar disorder. Minerva Pediatr 2011;63:183-200

18. Dickstein DP, Reidy BL, Pescosolido MF, et al. Translational neuroscience in pediatric bipolar disorder. Expert Rev Neurother 2011;11: 1699-701

19. Lan MJ, McLoughlin GA, Griffin JL, et al. Metabonomic analysis identifies molecular changes associated with the pathophysiology and drug treatment of bipolar disorder. Mol Psychiatry 2009;14: 269-79

20. Sanacora G, Zarate CA, Krystal JH, et al. Targeting the glutamatergic system to develop novel, improved therapeutics for mood disorders. Nat Rev Drug Discov 2008;7:426-37

21. Eastwood SL, Harrison PJ. Markers of glutamate synaptic transmission and plasticity are increased in the anterior cingulate cortex in bipolar disorder. Biol Psychiatry 2010;67:1010-16

22. Quiroz J, Gray N, Kato T, et al. Mitochondrially mediated plasticity in the pathophysiology and treatment of bipolar disorder. Neuropsychopharmacology 2008;33:2551-65

23. Manji H, Kato T, Di Prospero NA, et al. Impaired mitochondrial function in psychiatric disorders. Nat Rev Neurosci 2012;13:293-307

24. Konradi C, Eaton M, MacDonald ML, et al. Molecular evidence for mitochondrial dysfunction in bipolar disorder. Arch Gen Psychiatry 2004;61:300-08

25. Braitenberg B, Schüz A. Cortex: Statistics and Geometry of Neuronal Connectivity. Berlin: Springer-Verlag; 1998

26. Shen J, Petersen KF, Behar KL, et al. Determination of the rate of the glutamate/glutamine cycle in the human brain by in vivo 13C NMR. Proc Natl Acad Sci U S A 1999;96:8235-40

27. Lebon V, Petersen KF, Cline GW, et al. Astroglial contribution to brain energy metabolism in humans revealed by $13 \mathrm{C}$ nuclear magnetic resonance spectroscopy: elucidation of the dominant pathway for neurotransmitter glutamate repletion and measurement of astrocytic oxidative metabolism. J Neurosci 2002;22:1523-31

28. Rezin GT, Goncalves CL, Daufenbach JF, et al. Acute administration of ketamine reverses the inhibition of mitochondrial respiratory chain induced by chronic mild stress. Brain Res Bull 2009;79:418 -21

29. Diazgranados N, Ibrahim L, Brutsche NE, et al. A randomized add-on trial of an N-methyl-D-aspartate antagonist in treatmentresistant bipolar depression. Arch Gen Psychiatry 2010;67:793-802

30. Zarate CA Jr, Brutsche NE, Ibrahim L, et al. Replication of ketamine's antidepressant efficacy in bipolar depression: a randomized controlled add-on trial. Biol Psychiatry 2012;71:939-46

31. Dager SR, Corrigan NM, Richards TL, et al. Research applications of magnetic resonance spectroscopy to investigate psychiatric disorders. Top Magn Reson Imaging 2008;19:81-96

32. Maddock RJ, Buonocore MH. MR spectroscopic studies of the brain in psychiatric disorders. Curr Top Behav Neurosci 2012 Feb 1. [Epub ahead of print]

33. Yüksel C, Ongur D. Magnetic resonance spectroscopy studies of glutamate-related abnormalities in mood disorders. Biol Psychiatry 2010;68:785-94

34. Yildiz-Yesiloglu A, Ankerst DP. Neurochemical alterations of the brain in bipolar disorder and their implications for pathophysiology: a systematic review of the in vivo proton magnetic resonance spectroscopy findings. Prog Neuropsychopharmacol Biol Psychiatry 2006;30:969-95

35. Gigante AD, Bond DJ, Lafer B, et al. Brain glutamate levels measured by magnetic resonance spectroscopy in patients with bipolar disorder: a meta-analysis. Bipolar Disord 2012;14:478-87

36. Stork C, Renshaw PF. Mitochondrial dysfunction in bipolar disorder: evidence from magnetic resonance spectroscopy research. Mol Psychiatry 2005;10:900-19

37. Salvadore G, Zarate CA Jr. Magnetic resonance spectroscopy studies of the glutamatergic system in mood disorders: a pathway to diagnosis, novel therapeutics, and personalized medicine? Biol Psychiatry 2010;68:780-82

38. Geller B, Tillman R, Bolhofner K, et al. Child bipolar I disorder prospective continuity with adult bipolar I disorder; characteristics of second and third episodes; predictors of 8-year outcome. Arch Gen Psychiatry 2008;65:1125-33

39. Chang K. Adult bipolar disorder is continuous with pediatric bipolar disorder. Can J Psychiatry 2007;52:418-25

40. Axelson DA, Birmaher B, Strober MA, et al. Course of subthreshold bipolar disorder in youth: diagnostic progression from bipolar disorder not otherwise specified. J Am Acad Child Adolesc Psychiatry 2011;50:1001-16.e3

41. Kondo DG, Hellem TL, Sung YH, et al. Review: magnetic resonance spectroscopy studies of pediatric major depressive disorder. Depress Res Treat 2011;2011:650450

42. de Graaf RA. In Vivo NMR Spectroscopy: Principles and Techniques. West Sussex, England: John Wiley \& Sons; 2007

43. Keeler J. Understanding NMR Spectroscopy. Hoboken, New Jersey: Wiley; 2010

44. Agarwal N, Renshaw PF. Proton MR spectroscopy-detectable major neurotransmitters of the brain: biology and possible clinical applications. AJNR Am J Neuroradiol 2012;33:595-602

45. Kreis R, Ernst T, Ross BD. Development of the human brain: in vivo quantification of metabolite and water content with proton magnetic resonance spectroscopy. Magn Reson Med 1993;30:424-37

46. Dager S, Friedman S, Parow A, et al. Brain metabolic alterations in medication-free patients with bipolar disorder. Arch Gen Psychiatry 2004;61:450-58

47. Bates TE, Strangward M, Keelan J, et al. Inhibition of $\mathrm{N}$-acetylaspar tate production: implications for $1 \mathrm{H}$ MRS studies in vivo. Neuroreport 1996;7:1397-400

48. Pettegrew JW, McClure RJ, Panchalingam K. Spectroscopic imaging of schizophrenia. In: Shenton ME, Turetsky BI, eds. Understanding Neuropsychiatric Disorders: Insights from Neuroimaging. New York: Cambridge University Press; 2011:48-77

49. Friedman S, Dager S, Parow A, et al. Lithium and valproic acid treatment effects on brain chemistry in bipolar disorder. Biol Psychiatry 2004;56:340-48

50. Moore GJ, Galloway MP. Magnetic resonance spectroscopy: neurochemistry and treatment effects in affective disorders. Psychopharmacol Bull 2002;36:5-23

51. Chaumeil MM, Valette J, Guillermier M, et al. Multimodal neuroimaging provides a highly consistent picture of energy metabolism, validating 31P MRS for measuring brain ATP synthesis. Proc Natl Acad Sci U S A 2009;106:3988-93

52. Yildiz A, Sachs GS, Dorer DJ, et al. 31P Nuclear magnetic resonance spectroscopy findings in bipolar illness: a meta-analysis. Psychiatry Res 2001;106:181-91 
53. Shi XF, Kondo DG, Sung YH, et al. Frontal lobe bioenergetic metabolism in depressed adolescents with bipolar disorder: a phosphorus-31 magnetic resonance spectroscopy study. Bipolar Disord 2012;14:607-17

54. Sikoglu EM, Jensen JE, Vitaliano G, et al. Bioenergetic measurements in children with bipolar disorder: a pilot $31 \mathrm{P}$ magnetic resonance spectroscopy study. PLoS One 2013;8:e54536

55. Weber WA, Dudley J, Lee JH, et al. A pilot study of alterations in high energy phosphoryl compounds and intracellular $\mathrm{pH}$ in unmedicated adolescents with bipolar disorder. J Affect Disord 2013;150: 1109-13

56. Jeong EK, Sung YH, Kim SE, et al. Measurement of creatine kinase reaction rate in human brain using magnetization transfer imageselected in vivo spectroscopy (MT-ISIS) and a volume (31) P/(1) H radiofrequency coil in a clinical 3-T MRI system. NMR Biomed 2011;24:765-70

57. Brosnan JT, Brosnan ME. Creatine: endogenous metabolite, dietary, and therapeutic supplement. Annu Rev Nutr 2007;27:241-61

58. Brosnan ME, Edison EE, da Silva R, et al. New insights into creatine function and synthesis. Adv Enzyme Regul 2007;47:252-60

59. Schlattner U, Tokarska-Schlattner M, Wallimann T. Mitochondrial creatine kinase in human health and disease. Biochim Biophys Acta 2006;1762:164-80

60. Andres RH, Ducray AD, Schlattner U, et al. Functions and effects of creatine in the central nervous system. Brain Res Bull 2008;76: $329-43$

61. Hilsted J, Jensen KE, Thomsen C, et al. Maintenance of high-energy brain phosphorous compounds during insulin-induced hypoglycemia in men: 31P nuclear magnetic resonance spectroscopy study. Diabetes 1988;37:760-62

62. Petroff OA, Prichard JW, Behar KL, et al. Cerebral intracellular $\mathbf{p H}$ by 31P nuclear magnetic resonance spectroscopy. Neurology 1985; 35:781-88

63. Leibenluft E. Severe mood dysregulation, irritability, and the diagnostic boundaries of bipolar disorder in youths. Am J Psychiatry 2011;168:129-42

64. Zepf FD, Holtmann M. Disruptive mood dysregulation disorder. In: Rey JM, ed. IACAPAP e-Textbook of Child and Adolescent Mental Health. Geneva, Switzerland: International Association for Child and Adolescent Psychiatry and Allied Professions; 2012:111. Available at: http://iacapap.org/wp-content/uploads/E.3MOOD-DYSREGULATION-072012.pdf. Acessed December 29, 2013

65. American Psychiatric Association. Diagnostic and Statistical Manual of Mental Disorders, 5th Edition (DSM-5). Arlington, Virginia: American Psychiatric Publishing; 2013

66. Castillo M, Kwock L, Courvoisie H, et al. Proton MR spectroscopy in children with bipolar affective disorder: preliminary observations. AJNR Am J Neuroradiol 2000;21:832-38

67. Moore CM, Biederman J, Wozniak J, et al. Mania, glutamate/glutamine and risperidone in pediatric bipolar disorder: a proton magnetic resonance spectroscopy study of the anterior cingulate cortex. J Affect Disord 2007;99:19-25

68. Moore CM, Frazier JA, Glod CA, et al. Glutamine and glutamate levels in children and adolescents with bipolar disorder: a 4.0-T proton magnetic resonance spectroscopy study of the anterior cingulate cortex. J Am Acad Child Adolesc Psychiatry 2007;46:524-34

69. Cecil KM, DelBello MP, Sellars MC, et al. Proton magnetic resonance spectroscopy of the frontal lobe and cerebellar vermis in children with a mood disorder and a familial risk for bipolar disorders. J Child Adolesc Psychopharmacol 2003;13:545-55

70. Chang K, Adleman N, Dienes K, et al. Decreased N-acetylaspartate in children with familial bipolar disorder. Biol Psychiatry 2003;53: 1059-65

71. Sassi RB, Stanley JA, Axelson D, et al. Reduced NAA levels in the dorsolateral prefrontal cortex of young bipolar patients. Am J Psychiatry 2005;162:2109-15

72. Olvera RL, Caetano SC, Fonseca M, et al. Low levels of N-acetyl as- partate in the left dorsolateral prefrontal cortex of pediatric bipolar patients. J Child Adolesc Psychopharmacol 2007;17:461-73

73. Caetano SC, Olvera RL, Hatch JP, et al. Lower N-acetyl-aspartate levels in prefrontal cortices in pediatric bipolar disorder: a (1) $\mathrm{H}$ magnetic resonance spectroscopy study. J Am Acad Child Adolesc Psychiatry 2011;50:85-94

74. Patel NC, Cecil KM, Strakowski SM, et al. Neurochemical alterations in adolescent bipolar depression: a proton magnetic resonance spectroscopy pilot study of the prefrontal cortex. J Child Adolesc Psychopharmacol 2008;18:623-27

75. Davanzo P, Yue K, Thomas MA, et al. Proton magnetic resonance spectroscopy of bipolar disorder versus intermittent explosive disorder in children and adolescents. Am J Psychiatry 2003;160: 1442-52

76. Strawn JR, Patel NC, Chu WJ, et al. Glutamatergic effects of divalproex in adolescents with mania: a proton magnetic resonance spectroscopy study. J Am Acad Child Adolesc Psychiatry 2012;51: $642-51$

77. Young RC, Biggs JT, Ziegler VE, et al. A rating scale for mania: reliability, validity and sensitivity. Br J Psychiatry 1978;133:429-35

78. Davanzo P, Thomas MA, Yue K, et al. Decreased anterior cingulate myo-inositol/creatine spectroscopy resonance with lithium treatment in children with bipolar disorder. Neuropsychopharmacology 2001;24:359-69

79. Patel NC, DelBello MP, Cecil KM, et al. Lithium treatment effects on myo-inositol in adolescents with bipolar depression. Biol Psychiatry 2006;60:998-1004

80. Patel NC, DelBello MP, Cecil KM, et al. Temporal change in $\mathrm{N}$-acetyl-aspartate concentrations in adolescents with bipolar depression treated with lithium. J Child Adolesc Psychopharmacol 2008; 18:132-39

81. DelBello MP, Cecil KM, Adler CM, et al. Neurochemical effects of olanzapine in first-hospitalization manic adolescents: a proton magnetic resonance spectroscopy study. Neuropsychopharmacology 2006;31:1264-73

82. Chang K, Delbello M, Chu WJ, et al. Neurometabolite effects of response to quetiapine and placebo in adolescents with bipolar depression. J Child Adolesc Psychopharmacol 2012;22:261-68

83. Chang K, Karchemskiy A, Kelley R, et al. Effect of divalproex on brain morphometry, chemistry, and function in youth at high-risk for bipolar disorder: a pilot study. J Child Adolesc Psychopharmacol 2009;19:51-59

84. Gallelli KA, Wagner CM, Karchemskiy A, et al. N-acetylaspartate levels in bipolar offspring with and at high-risk for bipolar disorder. Bipolar Disord 2005;7:589-97

85. Singh M, Spielman D, Adleman N, et al. Brain glutamatergic characteristics of pediatric offspring of parents with bipolar disorder. Psychiatry Res 2010;182:165-71

86. Singh MK, Spielman D, Libby A, et al. Neurochemical deficits in the cerebellar vermis in child offspring of parents with bipolar disorder. Bipolar Disord 2011;13:189-97

87. Wozniak J, Gonenc A, Biederman J, et al. A magnetic resonance spectroscopy study of the anterior cingulate cortex in youth with emotional dysregulation. Isr J Psychiatry Relat Sci 2012;49:62-69

88. Achenbach TM, Edelbrock CS. Manual for the Child Behavior Checklist and Revised Child Behavior Profile. Burlington, Vermont: Department of Psychiatry, University of Vermont; 1983:230

89. Mick E, Biederman J, Pandina G, et al. A preliminary meta-analysis of the child behavior checklist in pediatric bipolar disorder. Biol Psychiatry 2003;53:1021-27

90. Biederman J, Wozniak J, Kiely K, et al. CBCL clinical scales discriminate prepubertal children with structured interview-derived diagnosis of mania from those with ADHD. J Am Acad Child Adolesc Psychiatry 1995;34:464-71

91. American Psychiatric Association. DSM-5 Childhood and Adolescent Disorders Work Group. Justification for Temper Dysregulation Disorder with Dysphoria: Introduction of a Diagnostic Category for Temper Dysregulation with Dysphoria (TDD) into the Mood Disorders Section 
of DSM-V. Arlington, Virginia: American Psychiatric Association; 2010

92. Leibenluft E, Charney DS, Towbin KE, et al. Defining clinical phenotypes of juvenile mania. Am J Psychiatry 2003;160:430-37

93. Dickstein DP, van der Veen JW, Knopf L, et al. Proton magnetic resonance spectroscopy in youth with severe mood dysregulation. Psychiatry Res 2008;163:30-39

94. Dickstein DP, Towbin KE, Van Der Veen JW, et al. Randomized double-blind placebo-controlled trial of lithium in youths with severe mood dysregulation. J Child Adolesc Psychopharmacol 2009; 19:61-73

95. Singh I, Rose N. Biomarkers in psychiatry. Nature 2009;460:202-07

96. Goodman WK, for the Research on Biomarkers for Mental Disorders. Concept Clearance: National Advisory Mental Health Council. Bethesda, Maryland: National Institute of Mental Health; 2009

97. Strakowski SM, Adler CM, Almeida J, et al. The functional neuroanatomy of bipolar disorder: a consensus model. Bipolar Disord 2012;14:313-25

98. Luykx JJ, Laban KG, van den Heuvel MP, et al. Region and state specific glutamate downregulation in major depressive disorder: a meta-analysis of (1)H-MRS findings. Neurosci Biobehav Rev 2012;36:198-205

99. Brady RO Jr, Cooper A, Jensen JE, et al. A longitudinal pilot proton MRS investigation of the manic and euthymic states of bipolar disorder. Transl Psychiatry 2012;2:e160

100. Brennan BP, Hudson JI, Jensen JE, et al. Rapid enhancement of glutamatergic neurotransmission in bipolar depression following treatment with riluzole. Neuropsychopharmacology 2010;35: $834-46$

101. Roybal DJ, Singh MK, Cosgrove VE, et al. Biological evidence for a neurodevelopmental model of pediatric bipolar disorder. Isr J Psychiatry Relat Sci 2012;49:28-43

102. Williams RS, Cheng L, Mudge AW, et al. A common mechanism of action for three mood-stabilizing drugs. Nature 2002;417:292-95

103. Bose S, French S, Evans FJ, et al. Metabolic network control of oxidative phosphorylation: multiple roles of inorganic phosphate. J Biol Chem 2003;278:39155-65

104. Brazy PC, Mandel LJ. Does availability of inorganic phosphate regulate cellular oxidative metabolism? News Physiol Sci 1986;1:100-03

105. Freeman D, Bartlett S, Radda G, et al. Energetics of sodium transport in the kidney: saturation transfer 31P-NMR. Biochim Biophys Acta 1983;762:325-36

106. Iotti S, Lodi R, Gottardi G, et al. Inorganic phosphate is transported into mitochondria in the absence of ATP biosynthesis: an in vivo 31P NMR study in the human skeletal muscle. Biochem Biophys Res Commun 1996;225:191-94

107. Brown GC. Control of respiration and ATP synthesis in mammalian mitochondria and cells. Biochem J 1992;284(pt 1):1-13

108. Balaban RS. Regulation of oxidative phosphorylation in the mammalian cell. Am J Physiol 1990;258:C377-89

109. Glinn M, Ni B, Paul SM. Inorganic phosphate enhances phospho- nucleotide concentrations in cultured fetal rat cortical neurons. Brain Res 1997;757:85-92

110. From AH, Zimmer SD, Michurski SP, et al. Regulation of the oxidative phosphorylation rate in the intact cell. Biochemistry 1990;29:3731-43

111. Zhang J, Shorr L, Yoshiyama M, et al. Hyperperfusion and cardioplegia effects on myocardial high-energy phosphate distribution and energy expenditure. Am J Physiol 1994;267:H894-904

112. Pedemonte $\mathrm{CH}$, Beauge L. Inhibition of $(\mathrm{Na}+, \mathrm{K}+)$-ATPase by magnesium ions and inorganic phosphate and release of these ligands in the cycles of ATP hydrolysis. Biochim Biophys Acta 1983;748:245-53

113. Apell HJ, Roudna M, Corrie JE, et al. Kinetics of the phosphorylation of Na,K-ATPase by inorganic phosphate detected by a fluorescence method. Biochemistry 1996;35:10922-30

114. Gatto C, Helms JB, Prasse MC, et al. Kinetic characterization of tetrapropylammonium inhibition reveals how ATP and Pi alter access to the $\mathrm{Na}+-\mathrm{K}+-\mathrm{ATPase}$ transport site. Am J Physiol Cell Physiol 2005;289:C302-11

115. Looney SW, el-Mallakh RS. Meta-analysis of erythrocyte Na,KATPase activity in bipolar illness. Depress Anxiety 1997;5:53-65

116. Chance B, Leigh JS Jr, Kent J, et al. Multiple controls of oxidative metabolism in living tissues as studied by phosphorus magnetic resonance. Proc Natl Acad Sci U S A 1986;83:9458-62

117. Erecińska M, Silver IA. Metabolism and role of glutamate in mammalian brain. Prog Neurobiol 1990;35:245-96

118. Hertz L. Intercellular metabolic compartmentation in the brain: past, present and future. Neurochem Int 2004;45:285-96

119. Rothman DL, De Feyter HM, de Graaf RA, et al. 13C MRS studies of neuroenergetics and neurotransmitter cycling in humans. $N M R$ Biomed 2011;24:943-57

120. Mason GF, Krystal JH. MR spectroscopy: its potential role for drug development for the treatment of psychiatric diseases. NMR Biomed 2006;19:690-701

121. Cardoso de Almeida JR, Phillips ML. Distinguishing between unipolar depression and bipolar depression: current and future clinical and neuroimaging perspectives. Biol Psychiatry 2013;73: $111-18$

122. Marsh R, Gerber AJ, Peterson BS. Neuroimaging studies of normal brain development and their relevance for understanding childhood neuropsychiatric disorders. J Am Acad Child Adolesc Psychiatry 2008;47:1233-51

123. Enzi B, Duncan NW, Kaufmann J, et al. Glutamate modulates resting state activity in the perigenual anterior cingulate cortex: a combined fMRI-MRS study. Neuroscience 2012;227:102-09

124. Hyder F, Rothman DL. Quantitative fMRI and oxidative neuroenergetics. Neuroimage 2012;62:985-94

125. Steen RG, Hamer RM, Lieberman JA. Measurement of brain metabolites by $1 \mathrm{H}$ magnetic resonance spectroscopy in patients with schizophrenia: a systematic review and meta-analysis. Neuropsychopharmacology 2005;30:1949-62

126. Kraguljac NV, Reid M, White D, et al. Neurometabolites in schizophrenia and bipolar disorder: a systematic review and meta-analysis. Psychiatry Res 2012;203:111-25 